\title{
Hybrid Polycaprolactone/Alginate Scaffolds Functionalized with VEGF to Promote de Novo Vessel Formation for the Transplantation of Islets of Langerhans
}

Citation for published version (APA):

Marchioli, G., Di Luca, A., de Koning, E., Engelse, M., Van Blitterswijk, C. A., Karperien, M., Van Apeldoorn, A. A., \& Moroni, L. (2016). Hybrid Polycaprolactone/Alginate Scaffolds Functionalized with VEGF to Promote de Novo Vessel Formation for the Transplantation of Islets of Langerhans. Advanced Healthcare Materials, 5(13), 1606-1616. https://doi.org/10.1002/adhm.201600058

Document status and date:

Published: 06/07/2016

DOI:

10.1002/adhm.201600058

Document Version:

Publisher's PDF, also known as Version of record

\section{Document license:}

Taverne

\section{Please check the document version of this publication:}

- A submitted manuscript is the version of the article upon submission and before peer-review. There can be important differences between the submitted version and the official published version of record. People interested in the research are advised to contact the author for the final version of the publication, or visit the DOI to the publisher's website.

- The final author version and the galley proof are versions of the publication after peer review.

- The final published version features the final layout of the paper including the volume, issue and page numbers.

Link to publication

\footnotetext{
General rights rights.

- You may freely distribute the URL identifying the publication in the public portal. please follow below link for the End User Agreement:

www.umlib.nl/taverne-license

Take down policy

If you believe that this document breaches copyright please contact us at:

repository@maastrichtuniversity.nl

providing details and we will investigate your claim.
}

Copyright and moral rights for the publications made accessible in the public portal are retained by the authors and/or other copyright owners and it is a condition of accessing publications that users recognise and abide by the legal requirements associated with these

- Users may download and print one copy of any publication from the public portal for the purpose of private study or research.

- You may not further distribute the material or use it for any profit-making activity or commercial gain

If the publication is distributed under the terms of Article 25fa of the Dutch Copyright Act, indicated by the "Taverne" license above, 


\title{
Hybrid Polycaprolactone/Alginate Scaffolds Functionalized with VEGF to Promote de Novo Vessel Formation for the Transplantation of Islets of Langerhans
}

\author{
Giulia Marchioli, Andrea Di Luca, Eelco de Koning, Marten Engelse, \\ Clemens A. Van Blitterswijk, Marcel Karperien, Aart A. Van Apeldoorn, \\ and Lorenzo Moroni*
}

Although regarded as a promising treatment for type 1 diabetes, clinical islet transplantation in the portal vein is still hindered by a low transplantation outcome. Alternative transplantation sites have been proposed, but the survival of extra-hepatically transplanted islets of Langerhans critically depends on quick revascularization after engraftment. This study aims at developing a new 3D scaffold platform that can actively boost vascularization and may find an application for extra-hepatic islet transplantation. The construct consists of a 3D ring-shaped polycaprolactone ( $P C L)$ scaffold with heparinized surface to electrostatically bind vascular endothelial growth factor (VEGF), surrounding a hydrogel core for islets encapsulation. Heparin immobilization improves the amount of VEGF retained by the construct, up to 3.6 fold, compared to untreated PCL scaffolds. In a chicken chorioallanthoic membrane model, VEGF immobilized on the construct enhances angiogenesis in close proximity and on the surface of the scaffolds. After 7 days, islets encapsulated in the alginate core show functional response to glucose stimuli comparable to free-floating islets. Thus, the developed platform has the potential to support rapid vascularization and islet endocrine function.
G. Marchioli, Prof. M. Karperien,

Prof. A. A. Van Apeldoorn

Department of Developmental BioEngineering

MIRA Institute for Biomedical Technology

and Technical Medicine

Faculty of Science and Technology

University of Twente

Drienerlolaan 5, 7522 NB Enschede, The Netherlands

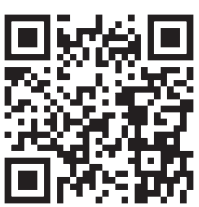

A. Di Luca, Prof. C. A. Van Blitterswijk, Prof. L. Moroni

Department of Tissue Regeneration

MIRA Institute for Biomedical Technology and Technical Medicine

Faculty of Science and Technology

University of Twente

Drienerlolaan 5, 7522 NB Enschede, The Netherlands

E-mail: I.moroni@maastrichtuniversity.nl

Prof. E. de Koning, Dr. M. Engelse

Department of Nephrology and Department of Endocrinology

Leiden University Medical Center

Albinusdreef 2, 2333 ZA Leiden, The Netherlands

Prof. C. A. Van Blitterswijk, Prof. L. Moroni

Department of Complex Tissue Regeneration

MERLN Institute for Technology Inspired Regenerative Medicine

Maastricht University

Universiteitssingel 40, 6229 ER Maastricht, The Netherlands

DOI: 10.1002/adhm.201600058

\section{Introduction}

The ability of islets of Langerhans to maintain their endocrine function is greatly influenced by a sufficient supply of oxygen and nutrients, which is normally maintained via a dense microvascular network within the islets. ${ }^{[1]}$ Normally, islets of Langerhans receive $5 \%-15 \%$ of the total pancreatic blood flow, which is extraordinary since they make up only $1 \%-2 \%$ of the total pancreatic tissue volume. ${ }^{[2]}$ Clinical islet transplantation (CIT) involves the isolation of islets from the surrounding exocine tissue in a donor pancreas, by the combination of enzymatic digestion and mechanical disruption followed by density centrifugation to purify the exocrine tissue. ${ }^{[3,4]}$ During this procedure, the pancreatic islet cells can lose their connection with the surrounding islet extracellular matrix due to enzymatic degradation. Consequently, the native microvasculature is disrupted. ${ }^{[5]}$ After their isolation and transplantation, islets can remain avascular for several days. ${ }^{[1]}$ An inadequate blood supply and delayed revascularization can induce islet necrosis, which ultimately leads to loss of function and lowers the survival of the transplanted cells. ${ }^{[1]}$ Together with the instant blood mediated inflammatory reaction, high concentrations of immunosuppresive drugs, high lipid and glucose concentrations, and mechanical stress, the lack of proper revascularization is one of the reasons why most islets are lost within the first few days after intrahepatic transplantation. ${ }^{[6,7]}$

To overcome the limitation of CIT, several alternative transplantation sites studied over the past decade, such as the renal capsule, an omental pouch, the intraperitoneum and subcutis, have been used with varying degree of success. ${ }^{[8,9]}$ Several different particular drawbacks are associated with each of these locations. The renal capsule is very thin and easy to tear compared to other locations, which makes transplantation of a large quantity of islets in human patients an extremely complicated intervention. Moreover, surgical access is difficult and not easily translatable to human clinical applications. ${ }^{[8]}$ The omental pouch and the peritoneum require an even higher number of islets to be transplanted compared to other sites. ${ }^{[8,9]}$ At this 
location, islets cannot be easily confined in a specific area, leading to distribution or migration over a large surface across the peritoneum. ${ }^{[8]}$ The subcutaneous location suffers from a high inflammatory response and usually lacks proper vascular access, which means that issues like long term oxygen and nutrient diffusion need to be addressed in an active manner. ${ }^{[9]}$ To further optimize islets transplantation at these alternative sites, scaffolds are often needed to provide confinement and mechanical protection to the transplanted islets. ${ }^{[10,11]}$ Furthermore, the use of such scaffolds can provide a supporting environment to convert inhospitable locations to suitable implantation sites. ${ }^{[1]}$ The main limitation of these scaffolds, however, is that they need to be quickly revascularized in order to provide the necessary supply of nutrient and oxygen to the transplanted tissue.

The capacity to induce construct revascularization is critical for engineering of complex tissues and organs of a clinically relevant size. In diabetes, and in general for scaffold-based regeneration of a variety of tissues, different strategies have been investigated. Revascularization of tissue-engineered constructs has been attempted by using either endothelial cells $(E C s),{ }^{[12]}$ endothelial progenitor cells, ${ }^{[13]}$ or embryonic stem cells ${ }^{[14]}$ to support the formation of new vasculature. An array of sponge-like scaffolds has been made from polymers, like PLLA and PLGA, using particulate leaching to create macroporous structures which can support the ingrowth of blood vessels. ${ }^{[14,15]}$ Polyethylene glycole based hydrogels in combination with glycosaminoglycans, ${ }^{[16-18]}$ and other synthetic and natural hydrogels, were used as growth factor delivery vehicles. These growth factor loaded hydrogels were shown to sustain a controlled release of growth factors in time, to support in vitro cell proliferation and new blood vessels formation in vivo. Due to its interaction with several growth factors, fibrin glue gel was also used as a controlled release system for vascular endothelial growth factor (VEGF), basic fibroblast growth factor (bFGF), and transforming growth factor beta. ${ }^{[19]}$ Gold, ${ }^{[20]}$ glass, and silica substrates ${ }^{[21]}$ have been used for micro contact printing, photolithography, and laser writing to provide patterned substrates capable of inducing directional growth of endothelial cells. ${ }^{[22]}$ Despite having showed promising results in terms of capillary and micro vasculature formation, these approaches may be limited when aiming at the regeneration of complex vessel networks for whole organs due to a limited control over the spatial presentation of growth factors in 3D. Other surgical techniques have also been proposed for the prevascularization of implanted tissue, like pedicle models ${ }^{[23]}$ or the creation of vessels loops in or around the scaffolds. ${ }^{[24-26]}$ These techniques are somewhat more complicated than direct implantaiton. Therefore, they might be more difficult to apply in patients. ${ }^{[27,28]}$

Growth factors can be directly injected in bolus into the area of interest, but this often leads to local overdoses of growth factors, and consequently to leaking vessels with an abnormal vessel structure. ${ }^{[29,30]}$ Therefore, several strategies to control the release of growth factors from biomaterials have been developed to prevent such abnormal tissue reactions. Growth factors can be adsorbed, ${ }^{[31]}$ incorporated, ${ }^{[16-18]}$ or covalently bound to biomaterials, ${ }^{[32]}$ which enables tuning of the release kinetics depending on the scaffold's degradation time. Spatial presentation of the growth factor, dose, and gradients are all characteristics that can play an important role in the establishment of a stable vascular network and, therefore, need to be carefully tuned to ensure proper vascularization. ${ }^{[22]}$ The controlled delivery of angiogenic growth factors, such as VEGF, bFGF, ${ }^{[33,34]}$ and platelet-derived growth factor $(\mathrm{PDGF})^{[31]}$ has been explored for enhancing the revascularization of implanted constructs. In particular, VEGF has been demonstrated as one of the critical regulators of neovascularization and has been also used in clinical studies. ${ }^{[35]}$ VEGF has been shown to stimulate the mobilization and recruitment of ECs, and to initiate and accelerate the process of angiogenesis. ${ }^{[36]}$ VEGF-mediated activation of the endothelial cells stimulates the production of matrix metalloproteinases, the subsequent degradation of the surrounding extracellular matrix, migration of ECs, and formation of buds and sprouts. Subsequently, the newly formed sprouts are elongated by the cell proliferation. ${ }^{[31]}$ For therapeutic angiogenesis to be effective, the growth factor dose, as well as the temporal and spatial presentation to the cells, needs to be carefully tuned.

Controlled growth factor delivery systems have been developed using hydrogels, ${ }^{[37,38]}$ microspheres, ${ }^{[39,40]}$ covalent functionalization of biomaterials, ${ }^{[41]}$ and electrostatic binding to heparin $(\mathrm{HEP})^{[42,43]}$ or heparan-sulfate molecules. Heparin has affinity for electrostatic binding of growth factors such as FGF-2, hepatocyte growth factor (HGF), and VEGF. ${ }^{[44,45]}$ This specific property of heparin plays an important role in many physiological processes, in which growth factors are required. ${ }^{[4]}$ Moreover, heparin is also present in the extracellular matrix where its ability to bind growth factors allows the storage of a large quantity of these signaling molecules in a readily available form, while preventing their degradation, ${ }^{[46]}$ thus facilitating their "on-demand" and controlled release mechanism when needed. ${ }^{[44,47]}$ Of particular importance in case of angiogenesis, a tuned release of growth factors can generate highly localized gradients that provide faster activation of signal transduction pathways involved in migration and differentiation of endothelial cells. ${ }^{[44]}$

In this study, we fabricated a macroporous ring-shaped polycaprolactone (PCL) scaffold decorated with VEGF-A in a spatially controlled manner, thus stimulating neo-angiogenesis in and around the implant. Human islets of Langerhans were contained in an alginate core in the center of the macroporous ring. The macroporous PCL ring was fabricated by 3D fiber deposition. Heparin was covalently bound to the polymer using 1-ethyl-3-(3-dimethylaminopropyl)carbodiimide/ $N$-hydroxy succinimide (EDC-NHS) chemistry and the scaffold was functionalized with electrostatically bound VEGF. We showed that with a relatively low amount of VEGF, neovascularization could be efficiently induced around and throughout the pores of the scaffold. Heparin that was covalently bound to the surface of the scaffolds enabled an efficient sequestration of VEGF, while islets encapsulated in the alginate core were viable and able to maintain their endocrine function over time.

\section{Results}

PCL plotted scaffolds resulted in a toroidal construct with an outer diameter of about $0.8 \mathrm{~cm}$, an inner diameter of $0.5 \mathrm{~cm}$, 

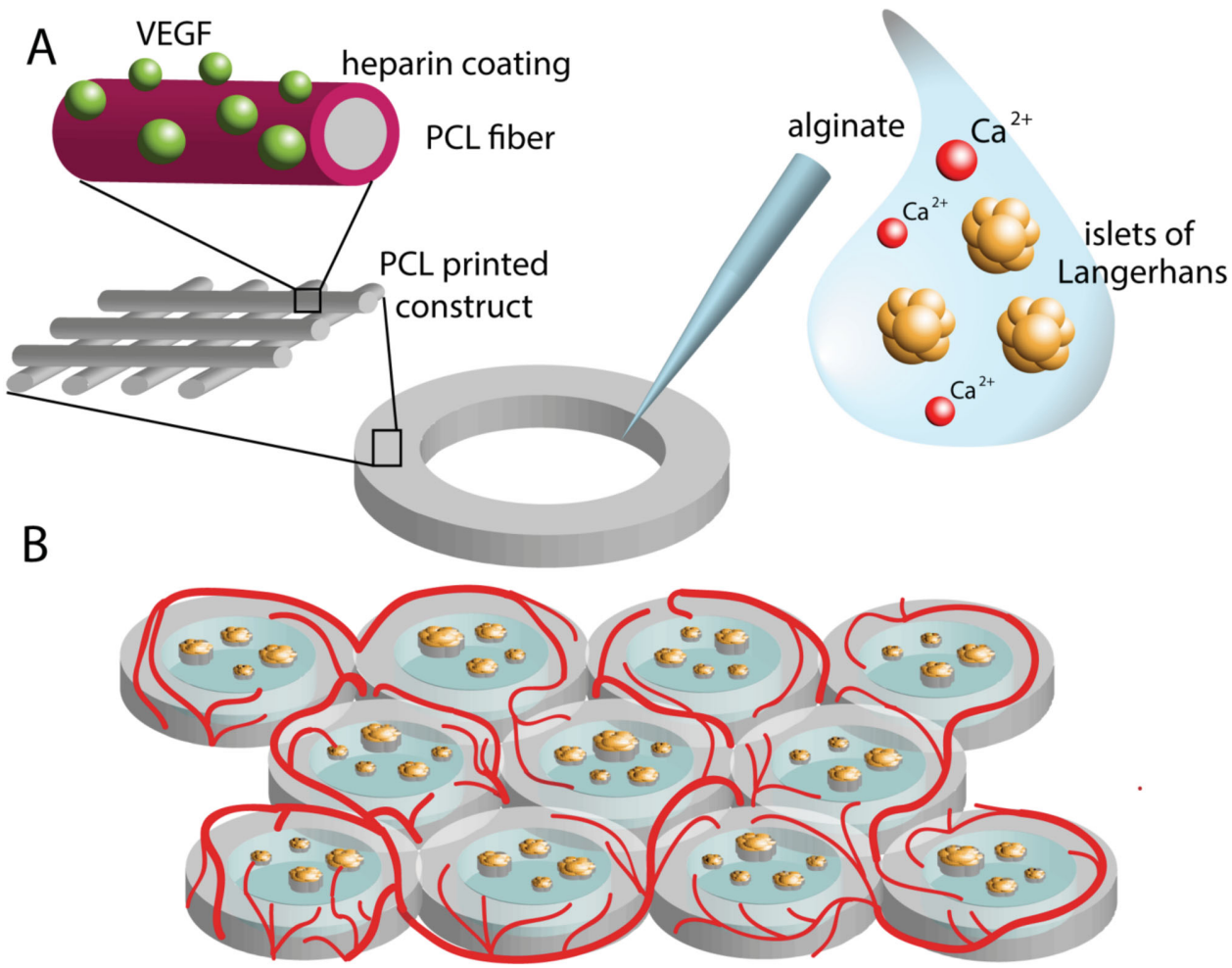

Figure 1. Schematic of the hybrid scaffold concept. 3D plotted polycaprolactone rings were covalently functionalized with a heparin layer. Heparin was used as an active linker to bind VEGF and protect it from degradation. A) Islets of Langerhans were encapsulated in the inner part of the structure using alginate hydrogel, crosslinked with $20 \times 10^{-3} \mathrm{M} \mathrm{CaCl}_{2}$. B) Multiple constructs can be printed one next to the other in a honeycomb configuration increasing the available surface for islets embedding and revascularization of the scaffold.

and a height of $1 \mathrm{~mm}$ (Figure 1). The fiber diameter of the unmodified PCL fibers was $210 \pm 25 \mu \mathrm{m}$ and the fiber spacing was $457 \pm 63 \mu \mathrm{m}$. After covalent couping of the PCL constructs with HEP, the fiber diameter was $192 \pm 14 \mu \mathrm{m}$ while the fiber spacing was reduced to $380 \pm 29 \mu \mathrm{m}$.

Azure staining proved complete and uniform heparin coating both on the 2D model surfaces (Figure S1A, Supporting Information) and on 3D plotted scaffolds (Figure 2A). The uniformity of heparin distribution on the scaffold surface was further confirmed by scanning electron microscopy (SEM) (Figures 1 and 2). After covalent binding of heparin to PCL the surface texture changed from a smooth surface into a rougher surface containing sub-micrometric features (Figure 2C-H). Heparin content was analyzed by quantifying the amount of nitrogen present on the scaffold by energy dispersive X-ray analysis (EDAX) analysis. The percentage of nitrogen after heparin immobilization was $15.5 \% \pm 4.1 \%$ of the elements composing the analyzed surface area, while in the noncoated scaffolds no nitrogen was detected on its surface (Figure 2B; Figure S2A (Supporting Information)). Efficacy of covalent binding of heparin to PCL via EDC-NHS chemistry was first determined on standardized 2D films of $1 \mathrm{~cm}$ in diameter (Table S1, Supporting Information) by quantification of the amount of heparin left in the immobilization solution after 15 hours. No heparin could be detected in the immobilization solution (Figure S1B, Supporting Information), indicating that almost all heparin was covalently bound to the polymer surface at a concentration of $1 \% \mathrm{w} \mathrm{v}^{-1}$ per $1.6 \mathrm{~cm}^{2}$ PCL surface.
PCL-heparinized scaffolds were exposed to three different concentrations of vascular endothelial growth factor (VEGF 200, 500, and $1000 \mathrm{ng} \mathrm{mL}^{-1}$ ) overnight. For all the three different VEGF loading amounts used, heparinized PCL scaffolds retained a much higher percentage of sequestered VEGF compared to the non-heparinized PCL scaffolds (Figure 3A). The percentage of immobilized VEGF was $77 \% \pm 3.9 \%$ in case of the $200 \mathrm{ng}$ initial loading and $61 \% \pm 4.6 \%$ in case of the $1000 \mathrm{ng}$ initial loading for heparinized scaffolds. The maximal percentage of VEGF unspecifically adsorbed on nonheparinized PCL scaffolds was $30 \% \pm 4.3 \%$, confirming the beneficial role of heparin for the electrostatic binding of VEGF onto the scaffold's surface. Doubling the initial VEGF load applied on the scaffold resulted in a double amount sequestered by the scaffold (Figure 3B), which implied that complete saturation of the available binding sites has not been reached yet.

Heparin coated scaffolds were not only able to retain a higher amount of VEGF compared to PCL scaffolds, but heparin functionalization also plays a role in reducing the initial burst release of unspecifically bound VEGF from scaffolds. The cumulative release from PCL non-heparinized scaffolds was higher than the corresponding concentration immobilized on heparin coated ones. After an initial burst release of VEGF, both heparinized and non-heparinized scaffolds displayed a comparable behavior with no or very limited additional VEGF release (Figure $3 \mathrm{C}$ ). In all the conditions tested, at the end of the test period of 14 days, the cumulative release was still very low, with the majority of the immobilized growth factor bound on the 
www.MaterialsViews.com
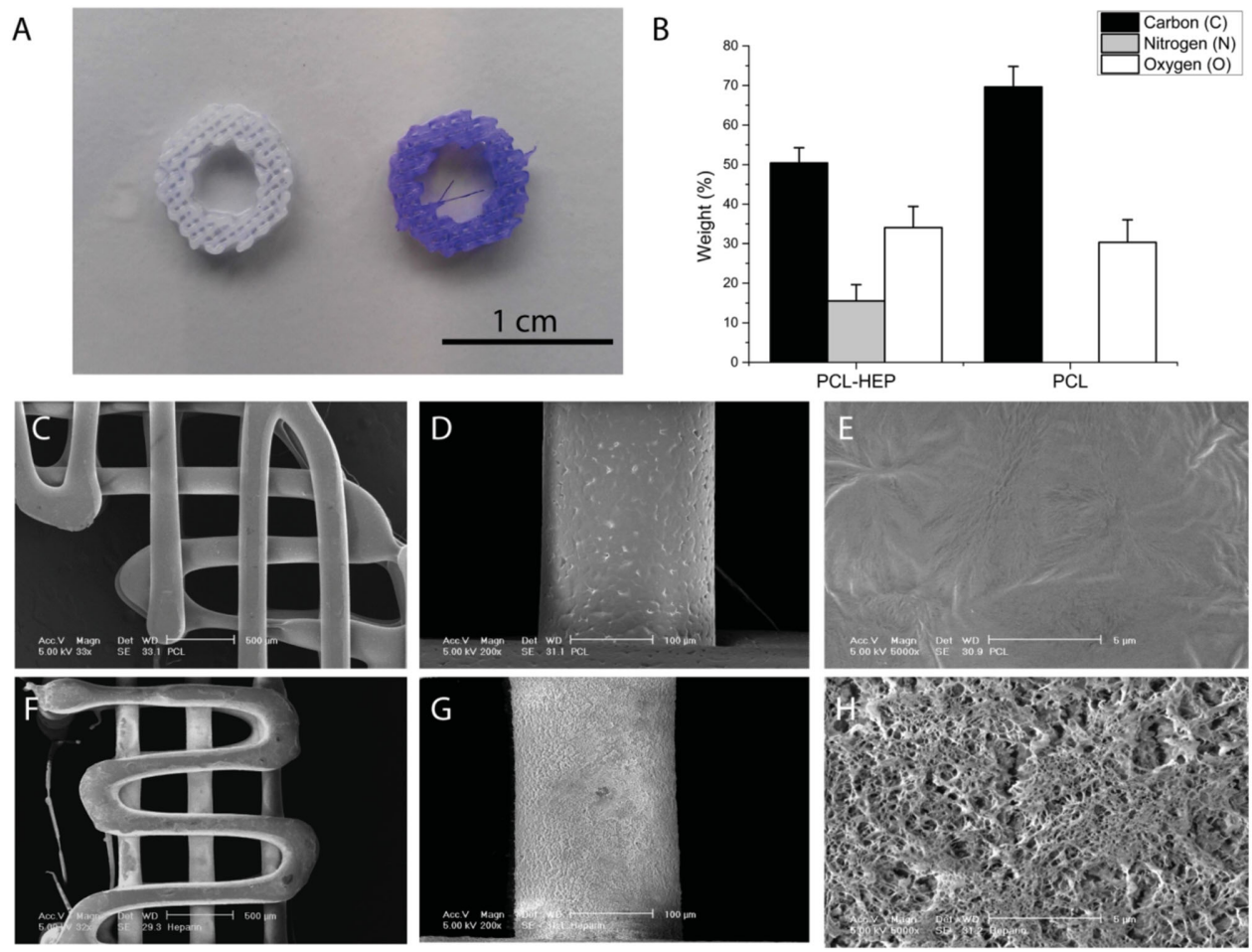

Figure 2. A) PCL and PCL/heparin plotted scaffolds stained with Azure II. B) Nitrogen quantification on heparin-coated versus bare PCL scaffolds Nitrogen accounted for the $15.5 \%\left(\mathrm{w} \mathrm{v}^{-1}\right)$ of the total isotope mass. $\left.\mathrm{C}-\mathrm{H}\right)$ SEM pictures at different magnifications of the bare PCL scaffolds (C-E) and of the heparinized constructs $(\mathrm{F}-\mathrm{H})$ where the change in surface topography can be appreciated.
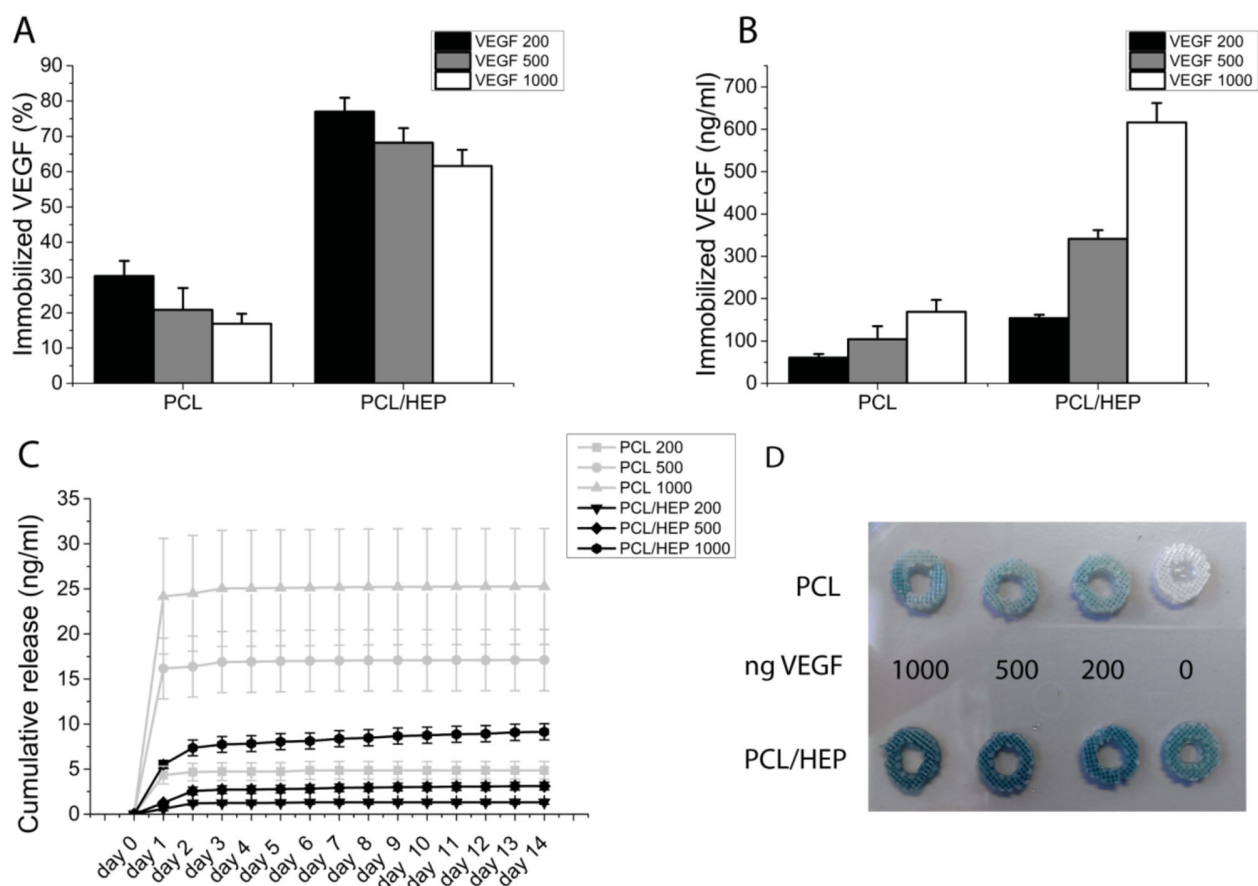

Figure 3. A) percentage of the initial amount of VEGF and B) total VEGF amount (ng) immobilized on the scaffold. Complete saturation of all the binding sites was not reached yet. C) Cumulative release of VEGF from PCL scaffolds compared to heparin coated PCL scaffold. The release kinetic was consistently decreased by the heparin layer in all the concentrations tested. D) Staining of the VEGF left on the scaffold after 15 days of release; the color intensity was higher in the heparin coated scaffolds, confirming a higher amount of VEGF retained by the coated scaffolds. 


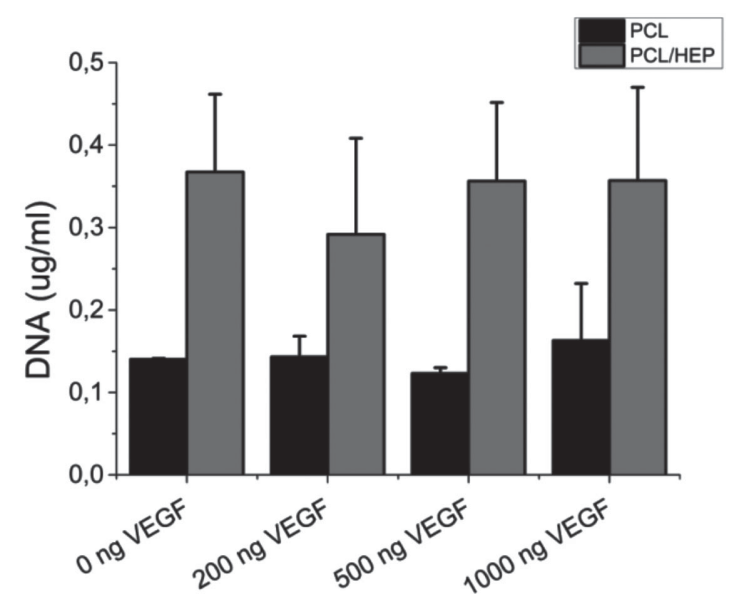

Figure 4. DNA quantification of HUVECs migrated from a monolayer culture to the 3D scaffolds. Heparin coating increased the amount of migrated cells, regardless of the VEGF concentration.

scaffold surface. To investigate whether VEGF was still present on the scaffolds after 15 days of release, scaffolds bound VEGF were stained. Heparin coated scaffolds displayed a higher color intensity, indicative of the presence of a higher VEGF amount (Figure 3D). The staining was consistently higher than the correspondent VEGF loading concentration on uncoated scaffolds.

Covalently bound heparin also increased cell attachment to the scaffold surface. The migration of human umbilical vein endothelial cells (HUVECs) cultured on tissue culture plastic onto the ring-shaped PCL scaffold increased on all heparin coated surfaces (Figure 4). Seeding efficiency of HUVECs on heparin coated PCL scaffolds increased compared to uncoated PCL scaffolds (Figure S3, Supporting Information). In both experiments, it seemed that the addition of increasing amounts of VEGF, both to heparin coated and uncoated scaffolds, did not influence the migratory movement or attachment of HUVECs in vitro. Furthermore, the metabolic activity of HUVECs was assessed after 1, 3, 5, and 7 days of culture, showing that cell viability was neither affected by heparin binding nor by the presence of VEGF (Figure S5, Supporting Information).

A chicken chorioallanthoic membrane (CAM) assay demonstrated that VEGF retained its bioactivity after electrostatic binding via heparin to the scaffolds. This was confirmed by the induction of neovascularization in close proximity and on top of the scaffolds in all of the VEGF concentrations used (Figure 5). Differences in blood vessel morphology were observed for different VEGF concentrations: vessels induced after loading with $200 \mathrm{ng}$ loading seemed leaky and had an immature appearance, whereas a lower induction of neovascularization, or even inhibition, was seen in the two other PCL conditions with a higher (500 and $1000 \mathrm{ng} \mathrm{mL}^{-1}$ ) VEGF loading. Conversely, in the heparin coated scaffolds new blood vessels were formed also on the surface of the scaffolds, in some cases guided by the fibers of the plotted 3D structures. The most effective VEGF concentration in inducing de novo vascularization on the construct was found to be $200 \mathrm{ng}$. Blood vessels with normal morphology were observed growing on the fibers or throughout the scaffolds' macropores. A lower amount of blood vessels could be also observed at the two higher loading concentrations (500 and
$1000 \mathrm{ng}$ ), comprising of leaky vessels in some cases (Figure 5). Unmodified PCL scaffolds showed no effect on de novo vessel formation, growth, and morphology, which was comparable to the morphology observed in the control membrane with no implant. Interestingly, an increase in blood vessels ingrowth toward the scaffold, although with a thinner diameter, was also induced by the presence of heparin coated scaffolds without VEGF. Analysis of vessel branching revealed an increasing branching with increasing VEGF concentration up to $500 \mathrm{ng}$ for PCL scaffolds. Interestingly, PCL/HEP scaffolds presented high branching independently from the amount of VEGF loaded, most likely due to the known capacity of heparin to bind endogenous factors as well (Figure S9, Supporting Information).

Islets encapsulated in the alginate in the central core of the scaffolds showed a rounded morphology and could be easily stained with dithizone, indicating the presence of insulin (Figure 6C). Islets embedded in the scaffold were responsive to glucose stimulation, with stimulation indexes as well as absolute insulin secretion comparable to free floating control islets (Figure 6A,B; Figures S4, S6, S7 and S8 (Supporting Information)). Alginate embedding, heparin, and VEGF immobilization on the polymer backbone did not cause reductions or inhibition in islets functionality.

\section{Discussion}

One of the major challenges to improve currently applied clinical islet transplantation is to convert a poorly vascularized site into a more favorable one, which could significantly improve islet functionality. Fast revascularization of the transplanted islets and connection to systemic circulation will ultimately result in increased nutrient and oxygen supply, increased viability, and enhanced islets response to glucose stimuli. In this study, we presented a novel scaffold fabrication strategy where islets can be encapsulated in an alginate core of the scaffold and are surrounded by a structure decorated with angiogenesis inducing factors via electrostatic binding to heparin. We showed that efficient covalent binding of heparin on the scaffolds was possible through standard NHS-EDC chemistry. Covalent binding of heparin affected the scaffold's surface topography by increasing the surface roughness. Heparin coating increased cell attachment on the scaffold surface compared to bare PCL and allowed absorption of a 3.6 times higher amount of VEGF compared to untreated PCL scaffolds. As showed in Figure 3B, a plateau value in the amount of immobilized VEGF was not reached yet, which means that additional growth factor can be loaded on the scaffolds. If needed, in future studies one could envision to use these available heparin sites to bind a second growth factor (e.g. bFGF) to the scaffolds to further modulate their vascularization potential. As also observed by other authors, this study showed that heparin can be efficiently used for the functionalization of biomaterials, ${ }^{[48-50]}$ for the reversible binding of growth factors, and for their controlled release. In our case, the results clearly show that the amount of VEGF immobilized on the scaffold is sufficient to elicit a vascular response already at the lowest concentration $(200 \mathrm{ng} \mathrm{mL}-1$ loading). On the other hand, the excess in heparin immobilization still provides free binding sites for serum proteins to 
Control
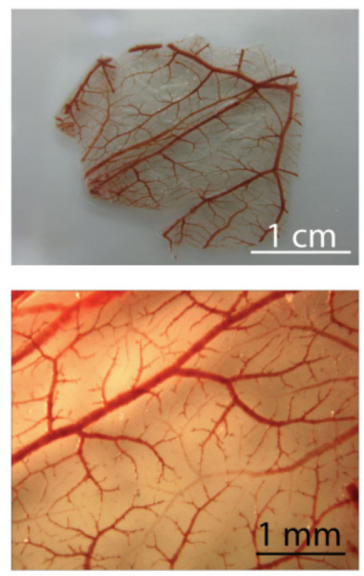

$\mathrm{PCL}$ 200 ng VEGF
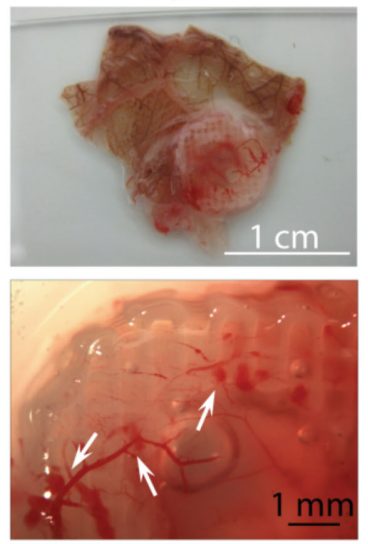

PCL/HEP 200 ng VEGF
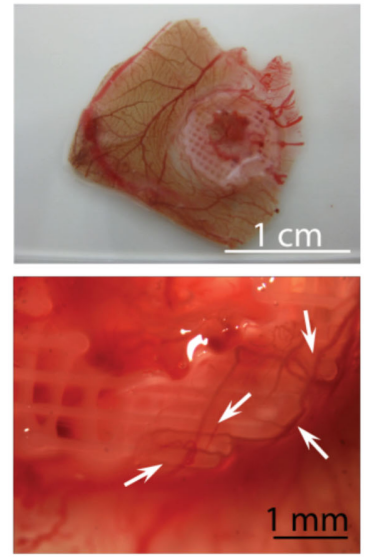

\section{PCL} 0 ng VEGF
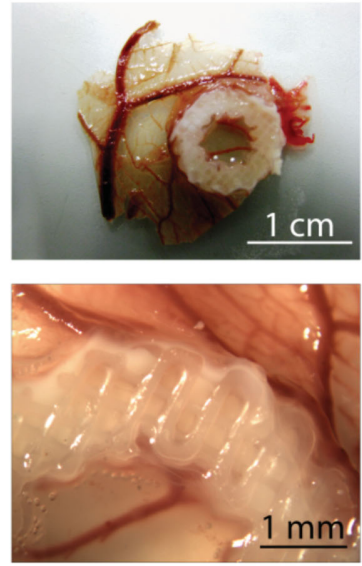

$\mathrm{PCL}$ 500 ng VEGF
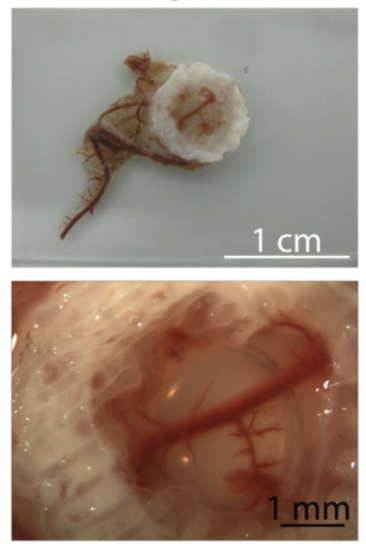

PCL/HEP $500 \mathrm{ng}$ VEGF
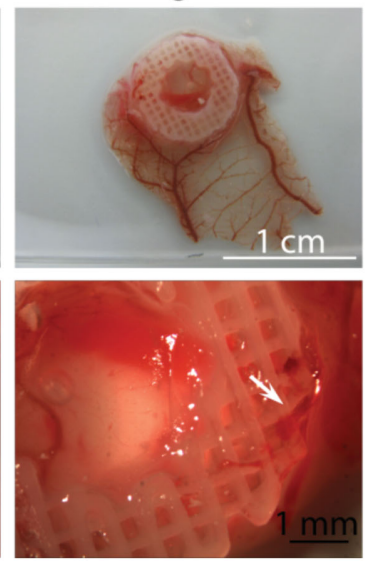

PCL/HEP 0 ng VEGF
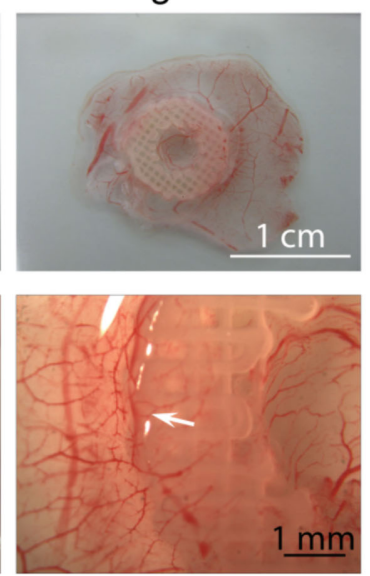

PCL 1000 ng VEGF
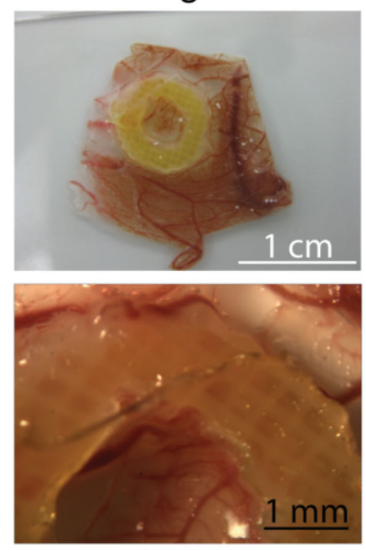

PCL/HEP 1000 ng VEGF
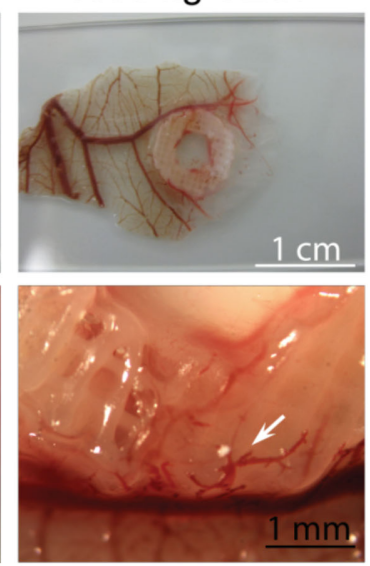

Figure 5. CAM assay performed with $P C L$ and heparin coated $P C L$ scaffolds with three different concentrations of VEGF. Leaking vessels were seen in the $200 \mathrm{ng}$ VEGF load on PCL scaffolds, while a higher VEGF concentration seemed to inhibit vessels formation. On heparin coated scaffolds, $200 \mathrm{ng}$ load VEGF seemed to induce the highest blood vessels formation, with normal morphology (Arrows indicate the blood vessel formation).

adsorb to the scaffold surface, thus increasing cell adhesion on the scaffold coated surface. A high heparin binding affinity

to VEGF has been already proven, among others, by Robinson et al. and Zhao et al. ${ }^{[51,52]}$ This was also demonstrated in this study by the fact that after 15 days of release, only a small percentage of the growth factor was released, while the great majority was still bound on the scaffolds. The burst release of VEGF detected on day 1 was already reduced up to 5 times in case of heparinized constructs for all the tested loading amounts. Such burst release could, therefore, be due to unspecific binding of VEGF to the surface of PCL scaffolds. In the following days VEGF was released at a concentration ranging between hundreds and tens of picomoles per liter, similar to what has been reported in literature to be the optimal concentration to elicit cell response $\left(10^{-9}-10^{-11} \mathrm{M}\right) \cdot{ }^{[53]}$ When considering translation to the clinics, the speed of such burst release could be actually reduced due to the presence of other proteins that would compete with VEGF for adsorption onto the PCL scaffolds.

VEGF functionalization of the scaffolds via heparin binding was able to induce an improvement of the vascularization in each of the three concentrations analyzed. Although the newly formed blood vessels appeared leaky in some conditions, the lowest VEGF concentration on heparin coated scaffolds provided new vessel formation with normal morphology. The best response was obtained with the $200 \mathrm{ng} \mathrm{mL}{ }^{-1}$ loading concentration, resulting in $154.0 \pm 7.8 \mathrm{ng}$ VEGF immobilized on the scaffold. It has been reported that a concentration threshold exists between normal and aberrant vascularization: too high VEGF production will lead to hemangiomas, while medium to low doses will lead to stable, not leaky capillaries. ${ }^{[54]}$ When this concept was applied to growth factor absorption on scaffolds, it was found that the most effective control of angiogenesis was not dependent on the total load of growth factor on the scaffolds, but on the gradient that developed upon release from the constructs into the surrounding environment. ${ }^{[54,55]}$ As shown by Chen et al., the most effective control of angiogenesis was achieved when the highest concentration in the developed gradient from the source scaffold to the surrounding environment was $100 \mathrm{ng} \mathrm{mL}{ }^{-1} \cdot{ }^{[5]}$ Not only the initial growth factor loading, but also the microenvironment gradient developed upon delivery could play a role in defining the directionality of the blood vessels. ${ }^{[55]}$ A $100 \mathrm{ng} \mathrm{mL} \mathrm{mL}^{-1}$ growth factor concentration initiated sprouting, but the developed gradient was not so steep to lose control over directionality. ${ }^{[55]}$ Moreover, 


\section{Day 1}

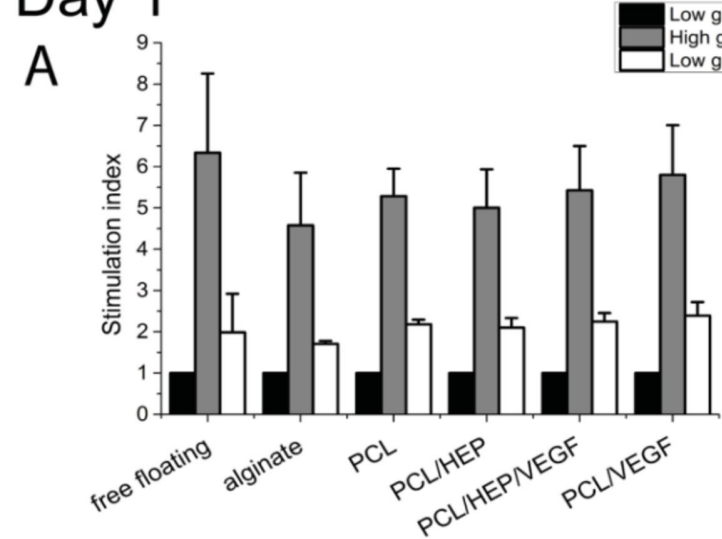

\section{Day 7}
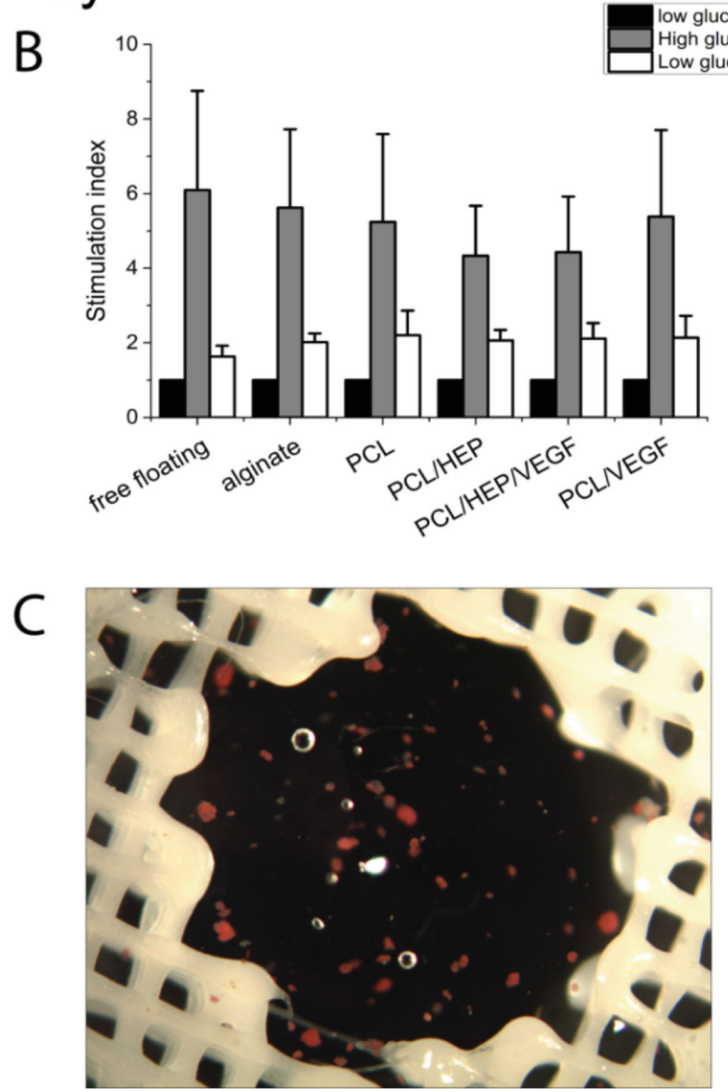

Figure 6. Functional behavior of islets at day 1 and day 7 when embedded in alginate bulk gels, in PCL-hybrid scaffolds and in the scaffolds coated with heparin and functionalized with VEGF. The results are the average of three donors. A, B) Pictures of islets embedded in $2 \%$ alginate gels in the C) 3D PCL-construct and islets stained with dithizone embedded in the same scaffold, after $1 \mathrm{~d}$ of culture.

the released growth factor dose can also exercise an influence over a normal or aberrant morphology of the newly formed blood vessels. ${ }^{[30]}$ It has been reported in literature that matrix bound VEGF is more effective in comparison to its soluble form in stimulating endothelial cells proliferation and maturation. ${ }^{[32]}$ In our test model, heparin functionalization of the construct and the tested loading concentration of $200 \mathrm{ng} \mathrm{mL}-1$ optimally meet these requirements for the potential revascularization of the implanted construct and could be used for enhancing islet viability and functionality after implantation. Further studies will aim at confirming such improved vascularization observed in the CAM model into a diabetic animal model as well. In doing so, we will also have to establish the degree of possible fibrosis due to the foreign body reaction of this implant and the implication of such a fibrotic reaction on vascularization and islet functionality.

HUVECs were used as a cell model to show endothelial cell migration toward the scaffold. Surprisingly, in the used setup no difference in cell migration was detected among the different VEGF concentrations. Heparin coating on the scaffold, though, was by itself responsible for an increased cell migration toward the scaffolds (Figure 4), for an improved cell seeding efficiency and adhesion on the scaffolds (Figure S3, Supporting Information), and increased blood vessel ingrowth in the CAM model (Figure 5). Considering the high protein binding capacities of heparin, a higher blood vessel ingrowth and branching on the heparinized scaffolds might be caused by increased serum protein absorption and thus increased cell adhesion on the heparin coated scaffolds. Moreover, the surface topography of the scaffolds increased upon heparin immobilization. This change in surface topography might increase the available surface for protein absorption. In addition, a change in the topography could provide better adhesion cues for the cells to adhere to, compared to a smooth PCL surface.

Islet embedding in a hydrogel located in the inner core of the scaffold protected islets from losing their round morphology. Islets were stained with dithizone showing the presence of insulin and a functional response to glucose stimulation, which was comparable in all the conditions tested. The stimulation index is defined as the amount of insulin secreted under high glucose stimulation divided by the amount secreted in basal, nonstimulated condition, and is typically used to give an indication of islets functionality. The actual values of secreted insulin $\left(\mathrm{mU} \mathrm{L}^{-1}\right)$ have also been reported and showed statistical significance in few cases for 2 out of 3 donors (Figures S6, S7, and S8, Supporting Information). Such analysis should be considered carefully. Significant differences between groups could be also the result of samples containing different number of islets, different beta cell mass within a single islet or islet with different size, which naturally range between 50 and $300 \mu \mathrm{m}$. The stimulation index excludes such differences in islet size and composition, and should therefore be considered as the main functionality quantitative readout. A low alginate concentration (2\%) could be used in such a construct, since weak mechanical properties of the hydrogel are compensated by the presence of the polymer ring around it, which provides mechanical support and keeps the islets confined in one location. A low alginate concentration is beneficial for islet encapsulation, because it prevents nutrients diffusion limitations that occur in a more concentrated hydrogel mesh. ${ }^{[56-58]}$ Diffusion limitations are also prevented by the presence of such a porous polymeric structure around them, which can provide mechanical support, without impairing oxygen, nutrients, and insulin diffusion.

So far, available cell-based strategies for neovascularization focused on the delivery of ECs or endothelial progenitor cells (EPCs), but it is not clear yet if the improvement in 
revascularization is given by these cells or by the angiogenic factors they secrete and research to identify the optimal cell source has still to be performed. ${ }^{[27]}$ Co-culture systems involving EPCs and other cell types of interest have been researched in an attempt to improve revascularization and are reviewed by Kirkpatrick et al. ${ }^{[59]}$ Other strategies involved the transplantation of genetically modified and transfected cells to induce stable expression of growth factor, but transfection also poses significant safety issues. ${ }^{[27,60,61]}$ More sophisticated approaches used advanced biofabrication techniques as photopatterning ${ }^{[62,63]}$ or micromachining ${ }^{[64]}$ to fabricate substrates for capillary networks growth in vitro, which would subsequently be implanted via microsurgical techniques. ${ }^{[27]}$ Although elegant, these approaches are also characterized by difficult applicability and translation to the clinic.

In most of the scaffold-based strategies developed for enhancing vascularization growth factors still play a pivotal role. Many studies have been performed in order to identify the ideal growth factor dose, release profile, ${ }^{[65]}$ attachment, ${ }^{[66]}$ or release strategy and growth factors combination. ${ }^{[17]}$ Release systems have been developed using hydrogels ${ }^{[16,17,66-68]}$ or other polymeric biomaterials. ${ }^{[13,22,38,69,70]}$ Covalent attachment of growth factors to the hydrogel matrix ${ }^{[66,69]}$ could hamper the protein functionality, because the covalent linkage could interfere with the protein folding. Other approaches, both on hydrogels and polymer, rely on the presence of heparin, hyaluronic acid, or other glycosaminoglycans to mimic more closely the natural extracellular matrix, provide reversible binding of the growth factor to the gel or polymer matrix and tailor binding and release in time. In addition to these advantages, our VEGFfunctionalized scaffolds can be easily produced, upscaled to host a relevant amount of cells and implanted without posing significant safety concerns.

The scaffold concept that we developed in this paper can be in principle applied not only to islets of Langerhans implantation but also to the transplantation of other cell types of interest. The scaffold structure could be easily expanded to accommodate a clinically relevant amount of islets for transplantation, without impairing nutrient diffusion. Islet embedding in the alginate core of the scaffold did not impair islet functionality and could possibly provide immuno protection properties. Heparin functionalization and VEGF immobilization did not affect insulin secretion from the scaffold or cause an adverse effect on islet functionality. Adjacent polymers rings can be plotted in a honeycomb configuration, increasing the spots available for islet embedding and still having a network of blood vessels surrounding these islet-specific areas from all sides (Figure 1B).

Typically, between a few hundreds up to 10000 islets equivalent are transplanted per kilogram of the patient, where the exact number depends on availability and the clinical condition. ${ }^{[71]}$ Human islets transplantation in the portal vein has a limited possibility to succeed and the yield is so low that often the patients require multiple islet injections to reach a therapeutic level of insulin production. Islets often die in the short period after transplantation. Extra hepatic islet transplantation is a valid alternative to create a more favorable environment for islets, but even in this case cell viability is reduced after a few days from surgery. Therefore, a device for islets transplantation and confinement is required to maintain cell viability in time.
Alginate has been a widely used material for islets encapsulation. A remarkable approach has been proposed by Dufrane and co-workers where islets have been implanted in alginate sheets with good results. ${ }^{[72]}$ It is anyway well recognized in the field that devices used for islet transplantation must take into consideration nutrient and oxygen diffusion to assure proper cell functionality into the transplanted tissue. The proposed route for implantation of our developed construct is a simple one-step procedure in a subcutaneous location. An alternative approach for using this scaffold in the clinics is given by a subcutaneous implantation of the heparinized-PCL ring only, followed by injections of the islets in a hydrogel in the central core. The preimplantation of the ring would prepare a highly vascularized subcutaneous location for islet implantation, which would be a more favorable environment for the islets to reside in. Once the vascular bed is ready, $\approx 15$ days later, injection of the islet in the central core of the scaffold could take place. A standard regime of immunosuppression should be considered in combination with such a device, unless specific studies are performed to optimize the specific type of alginate and obtain a mesh size that is tight enough to protect islets from immune rejection without compromising nutrient diffusion and insulin secretion.

\section{Conclusions}

This study demonstrates that heparin immobilization is a simple and convenient strategy for controlled delivery of VEGF and its protection from degradation. The bound VEGF was able to induce a normal angiogenic response in a CAM model at a

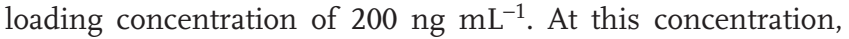
the 3D fiber configuration of the plotted scaffolds may provide a substrate where blood vessels ingrowth toward the islets is facilitated. Islets embedded in the scaffold were functional and responded normally to glucose stimulation. This scaffold can be regarded as a potentially new approach for subcutaneous islet transplantation and improvement of revascularization, addressing one of the most important limitations in the currently applied procedures for islet transplantation.

\section{Experimental Section}

Scaffold Fabrication: PCL scaffolds (Sigma, Zwijndrecht, the Netherlands) were fabricated using an extrusion-based additive manufacturing machine (sysENG, Germany). PCL (mW 45 000) was heated to $100^{\circ} \mathrm{C}$. Plotting speed and pressure were set respectively to $175 \mathrm{~mm} \mathrm{~min}{ }^{-1}$ and 5 bars. A needle of $200 \mu \mathrm{m}$ in diameter was used for extrusion. Scaffolds were plotted in a 0-90 fiber deposition configuration in a toroidal shape with an $8 \mathrm{~mm}$ outer diameter, a $4 \mathrm{~mm}$ inner diameter, and $1 \mathrm{~mm}$ height. For each layer, fiber thickness was set to $150 \mu \mathrm{m}$ and fiber spacing to $600 \mu \mathrm{m}$.

Heparin coating on PCL scaffolds was performed by dissolving $1 \% \mathrm{w} \mathrm{v}^{-1}$ heparin (Sigma, Zwijndrecht, the Netherlands) in $0.05 \mathrm{M}$ 2-(N-morpholino)ethanesulfonic acid) (MES) buffer (Sigma, Zwijndrecht, the Netherlands) at a pH of 5.5. $0.5 \mathrm{~m}$ 1-ethyl-3-(3-dimethylaminopropyl) carbodiimide (EDC) and $0.5 \mathrm{~m} \mathrm{~N}$-hydroxysuccinimide (NHS) (Sigma, Zwijndrecht, the Netherlands) were added to the heparin solution. Scaffolds were previously equilibrated for $15 \mathrm{~min}$ in MES buffer and subsequently immersed in the reaction mixture. The reaction was stirred for $15 \mathrm{~h}$ at room temperature. The reaction was stopped by extensively 
washing the scaffolds with sterile $\mathrm{H}_{2} \mathrm{O}$ to remove all the residues of unbound heparin. ${ }^{13,50]}$

Vascular endothelial growth factor (VEGF Peprotech, London, UK) was diluted to the loading concentrations of 200,500, and $1000 \mathrm{ng} \mathrm{mL}^{-1}$ in phosphate buffer saline solution (PBS) (Gibco, Grand Island, USA) supplemented with $0.1 \% \mathrm{wt}^{-1}$ bovine serum albumin (Sigma, Zwijndrecht, the Netherlands). Each scaffold was immersed in VEGF solution $(1 \mathrm{~mL})$ for $24 \mathrm{~h}$ at $4{ }^{\circ} \mathrm{C}$ to allow absorption of the growth factor on the scaffold surface.

The central open core of the scaffold was filled with $2 \% \mathrm{w} \mathrm{v}^{-1}$ ultrapure alginate in PBS (courtesy of Paul de Vos, UMCG, Groningen) and crosslinked for $5 \mathrm{~min}$ with a $20 \times 10^{-3} \mathrm{M}$ calcium chloride solution (Sigma, Zwijndrecht, the Netherlands) in $10 \times 10^{-3} \mathrm{M}$ HEPES (Invitrogen, Grand Island, USA). Scaffolds were then washed with tris-buffered saline (TBS).

Heparin Staining and Heparin Quantification: Staining of the heparin coating on PCL scaffolds was performed by immersion of the treated scaffolds in a $0.01 \mathrm{mg} \mathrm{mL}^{-1}$ Azure II solution (Sigma, Zwijndrecht, the Netherlands). Before imaging, scaffolds were extensively washed with water. ${ }^{[73]}$ The heparin left in the reaction mixture after $15 \mathrm{~h}$ immobilization was quantified with a colorimetric assay based on Azure II, as reported by Gutowska et al. ${ }^{[73]}$ Briefly, $0.5 \mathrm{~mL}$ of the reaction blend was mixed with $0.01 \mathrm{mg} \mathrm{mL}^{-1}$ Azure II solution $(4.5 \mathrm{~mL})$. The absorption of the heparinAzure II complex was measured after $1 \mathrm{~min}$ at $500 \mathrm{~nm}$, and compared with a reference curve. The amount of heparin immobilized on the scaffolds, was calculated by difference with the initial heparin loading.

SEM and EDAX: PCL scaffolds and heparin-coated PCL scaffolds were gold sputtered (Cressington sputter coater 108 auto) and analyzed by scanning electron microscopy (Philips-XL 30 ESEM-FEG). SEM images were taken at different magnifications $(33 \times, 200 \times$, and 5000X) with an accelerating voltage of $5 \mathrm{kV}$. Scaffold features such as fiber diameter, fiber spacing, and layer thickness were analyzed using Image J software.

Surface coating of the scaffolds was investigated using SEM equipped with an EDAX (Ametek, USA). Magnification was kept the same as before while voltage was increased to $10 \mathrm{kV}$. Point analysis for the chemical composition at various random spots of the scaffolds was performed and the quantification of Carbon (C), Oxygen (O), and Nitrogen $(\mathrm{N})$ was obtained. The nitrogen content was related to the amount of immobilized heparin.

VEGF Immobilization Efficiency and Release Study: VEGF-A immobilization efficiency on PCL and PCL/HEP scaffolds was quantified by ELISA (R\&D, Minneapolis, USA) by measuring the amount of VEGF left in the immobilization medium after $24 \mathrm{~h}$ absorption and calculating the difference with the total amount placed in solution. Similarly, the amount of VEGF released daily in PBS $/ 0.1 \%$ BSA $(0.5 \mathrm{~mL})$ was also quantified by ELISA. The amount of VEGF left on the scaffold after 15 days of release was stained with an adaptation of the ELISA kit from Peprotech (Peprotech, London, UK). Briefly, VEGF still bound on the scaffold was stained with a biotinilated-anti-VEGF antibody, which was subsequently detected with avidin-peroxidase and 2,2'-azino-bis(3ethylbenzothiazoline-6-sulphonic acid) substrate.

Chicken Chorioallanthoic Membrane Assay: Neovascularization potential of the PCL and PCL-HEP coated scaffolds with VEGF (loading concentration $0,200,500$, and $1000 \mathrm{ng} \mathrm{mL}^{-1}$ ) was tested using a chicken CAM assay. Fertilized leghorn chicken eggs were purchased from a local farm and incubated for 3 days at $37^{\circ} \mathrm{C}$ at an $80 \%$ humidity and regularly turned. On the fourth day, a window of circa $1 \mathrm{~cm} \times 1 \mathrm{~cm}$ was opened in the shell and the next day samples were implanted. Scaffolds were prepared as previously explained and implanted after $4 \mathrm{hrs}$ incubation in a PBS solution with $0.1 \%$ BSA to get rid of the burst release of weakly bound VEGF. PCL/VEGF and PCL/HEP/VEGF scaffolds were implanted in the eggs for 4 days, before the chicken embryos were sacrificed with an ethanol injection. The membrane with the scaffold was fixed with formalin and excised for further imaging. ${ }^{[74]}$ Vessel branching analysis was performed by manually counting the amount of branches on at least three different microscopy pictures.

Migration and Cell Viability Assays: To assess the potential of the $\mathrm{PCL} / \mathrm{HEP}$ scaffolds loaded with VEGF to attract endothelial precursor cells for the improvement of vascularization in vivo, the migration of HUVECs toward the scaffold was tested in vitro. HUVECs (Lonza, Basel, Switzerland) were used as a model and cultured at $37^{\circ} \mathrm{C}$, in a $5 \% \mathrm{CO}_{2}$ incubator, in EBM-2 basal medium (Lonza, Basel, Switzerland) supplemented with $2 \%$ FBS and growth factors (bullet kit EGM-2, Lonza, Basel, Switzerland).

85500 cells/well were seeded in a 24-well plate. One day after seeding, cells were treated for $2 \mathrm{~h}$ with a $0.5 \mathrm{mg} \mathrm{mL}$-1 solution of Mitomycin C (Sigma, Zwijndrecht, the Netherlands) in culture medium to block cell proliferation, followed by a washing step with PBS.

We prepared PCL and PCL-HEP coated scaffolds loaded with VEGF concentrations of $0,200,500$, and $1000 \mathrm{ng} \mathrm{mL}^{-1}$. Immediately after VEGF immobilization, samples were incubated in complete EGM-2 medium for $2 \mathrm{~h}$, to increase serum protein absorption on the scaffold surface to enable cell attachment. After this preincubation step, samples were removed and placed on top of the previously cultured HUVECs monolayer in EGM-2 medium without addition of VEGF. After 2 days, the scaffolds were cut, immersed in water and sonicated to lyse the HUVECs which had migrated onto the scaffold surface. After cell-lysis, DNA was quantified using a Pico Green assay (Invitrogen, Grand Island, USA) and related to total cell number. HUVECs' metabolic activity on day 1, 3, 5, and 7 was assessed using a PrestoBlue Cell Viability kit (Life technologies), according to the manufacturer's protocol. Briefly, cultured medium was replaced with a medium containing $10 \%(\mathrm{v} / \mathrm{v})$ PrestoBlue reagent and cells were incubated for $1 \mathrm{hr}$ at $37^{\circ} \mathrm{C}$. Fluorescence was measured at $590 \mathrm{~nm}$ on a Perkin Elmer Victor3 1420 multiple plate reader.

Islets of Langerhans Culture: Human islets of Langerhans were provided by the islet isolation and transplantation centre at the Leiden University Medical Centre with informed consent. Human islets were cultured in CMRL medium (Cellgro, Manassas, USA) supplemented with 10\% FBS (Lonza, Basel, Switzerland) and 1\% Pen/Strep (Gibco, Grand Island, USA). ${ }^{[75]}$

For islet encapsulation in the scaffold core, islets were handpicked and resuspended in a $2 \% \mathrm{w} \mathrm{v}^{-1}$ ultrapure alginate solution in PBS. Subsequently, islets were mixed in alginate $\left(1330\right.$ islets $\left.\mathrm{mL}^{-1}\right)$ and a droplet $(15 \mu \mathrm{L})$ of islet-alginate mixture was deposited on a hydrophobic polystyrene surface. This resulted in alginate constructs containing 20 islets in average. The PCL or PCL-HEP coated scaffold was placed around each droplet. Alginate was crosslinked with a $20 \times 10^{-3} \mathrm{M}$ calcium chloride solution for $5 \mathrm{~min}$ and the resulting hybrid constructs were subsequently washed in TBS solution. The above mentioned fabrication method resulted in encapsulation of circa 20 islets per hybrid scaffold or in alginate droplets only. Glucose responsiveness was evaluated by a glucose induced insulin secretion test (GIIST). The functional response of islets embedded in alginate only and in the hybrid construct was compared to the same number of free floating islets in nonadherent tissue culture plates.

GIIST: Human islets were incubated for $1.5 \mathrm{hr}$ in a Krebs-Ringer buffer with $1.67 \times 10^{-3} \mathrm{M}$ glucose, to ensure stabilization of beta cell insulin secretion. Subsequently, islets were incubated for $1.5 \mathrm{hr}$ in a low glucose Krebs-Ringer buffer $\left(1.67 \times 10^{-3} \mathrm{M}\right.$ glucose $)$ after which medium samples were taken for ELISA. Islets were then incubated for an equal amount of time in a high glucose $\left(16.7 \times 10^{-3} \mathrm{M}\right)$ containing medium, followed by low glucose $\left(1.67 \times 10^{-3} \mathrm{M}\right)$ medium, while medium samples were taken after each step for ELISA. All medium samples were analyzed for insulin content using ELISA kits (Mercodia, Uppsala, Sweden). Plates were scanned using a Multiskan GO Microplate Spectrophotometer (Thermo scientific, Breda, the Netherlands) and insulin release profiles were calculated according to the manufacturer's protocol.

Statistical Analysis: Statistical analysis was performed using ANOVA mean comparison, followed by a Tuckey's posthoc test. Data are represented as mean \pm standard deviation.

\section{Supporting Information}

Supporting Information is available from the Wiley Online Library or from the author. 


\section{Acknowledgements}

This research is part of the Diabetes Cell Therapy Initiative (DCTI). It was subsidized by the Dutch Diabetes fund and the Ministry of economic affairs (FES program) of the Netherlands. This work was also financially supported by the Technologiestichting STW, OTP Grant 11135. The authors acknowledge Dr. Paul the Vos for kindly providing the ultrapure alginate. The authors declare no existing conflict of interest in the publication of this manuscript.

Received: January 18, 2016 Revised: March 16, 2016 Published online: April 26, 2016

[1] M. Brissova, A. C. Powers, Diabetes 2008, 57, 2269.

[2] J. A. Williams, I. D. Goldfine, Diabetes 1985, 34, 980

[3] A. M. J. Shapiro, J. R. T. Lakey, E. A. Ryan, G. S. Korbutt, E. Toth, G. L. Warnock, N. M. Kneteman, R. V. Rajotte, N. Engl. J. Med. 2000, 343, 230.

[4] C. Ricordi, P. E. Lacy, D. W. Scharp, Diabetes 1989, 1, 140.

[5] A. R. Pepper, B. Gala-Lopez, O. Ziff, A. M. Shapiro, Clin. Dev. Immunol. 2013, 2013, 352315.

[6] A. C. Brady, M. M. Martino, E. Pedraza, S. Sukert, A. Pileggi, C. Ricordi, J. A. Hubbell, C. L. Stabler, Tissue Eng. A 2013, 19, 2544.

[7] E. Pedraza, A. C. Brady, C. A. Fraker, R. D. Molano, S. Sukert, D. M. Berman, N. S. Kenyon, A. Pileggi, C. Ricordi, C. L. Stabler, Cell Transplant. 2013, 22, 1123.

[8] S. Merani, C. Toso, J. Emamaullee, A. M. J. Shapiro, Br. J. Surgery 2008, 95, 1449.

[9] E. Cantarelli, L. Piemonti, Curr. Diabetes Rep. 2011, 11, 364.

[10] D. J. Borg, E. Bonifacio, Curr. Diabetes Rep. 2011, 11, 434.

[11] J. A. Giraldo, J. D. Weaver, C. L. Stabler, J. Diabetes Sci. Technol. 2010, 4, 1238

[12] M. R. Williamson, R. Black, C. Kielty, Biomaterials 2006, 27, 3608.

[13] S. Singh, B. M. Wu, J. C. Dunn, Tissue Eng. A 2011, 17, 1819.

[14] S. Levenberg, J. S. Golub, M. Amit, J. Itskovitz-Eldor, R. Langer, Proc. Natl. Acad. Sci. USA 2002, 99, 4391.

[15] J. E. P. Nor, M. C. Peters, J. B. Christensen, M. M. Sutorik, S. Linn, M. K. Khan, C. L. Addison, D. J. Mooney, P. J. Polverini, Lab Invest. 2001, 81, 10.

[16] A. Zieris, S. Prokoph, K. R. Levental, P. B. Welzel, M. Grimmer, U. Freudenberg, C. Werner, Biomaterials 2010, 31, 7985.

[17] R. A. Peattie, E. R. Rieke, E. M. Hewett, R. J. Fisher, X. Z. Shu, G. D. Prestwich, Biomaterials 2006, 27, 1868.

[18] D. B. Pike, S. Cai, K. R. Pomraning, M. A. Firpo, R. J. Fisher, X. Z. Shu, G. D. Prestwich, R. A. Peattie, Biomaterials 2006, 27, 5242.

[19] P. P. Spicer, A. G. Mikos, J. Controlled Release 2010, 148, 49.

[20] C. S. Chen, M. Mrksich, S. Huang, G. M. Whitesides, D. E. Ingber, Biotechnol. Prog. 1998, 14, 356.

[21] S. Kaihara, J. Borenstein, R. Koka, S. Lalan, E. R. Ochoa, M. Ravens, H. Pien, B. Cunningham, J. P. Vacanti, Tissue Eng. 2000, 6, 105.

[22] G. Papavasiliou, M. H. Cheng, E. M. Brey, J. Investig. Med. 2010, 58, 838.

[23] M. L. Moya, M. H. Cheng, J. J. Huang, M. E. Francis-Sedlak, S. W. Kao, E. C. Opara, E. M. Brey, Biomaterials 2010, 31, 2816.

[24] R. Mian, W. A. Morrison, J. V. Hurley, A. J. Penington, R. Romeo, Y. Tanaka, K. R. Knight, Tissue Eng. 2000, 6, 595.

[25] R. A. Mian, K. R. Knight, A. J. Penington, J. V. Hurley, A. Messina, R. Romeo, W. A. Morrison, Tissue Eng. 2001, 7, 73.

[26] Y. Tanaka, K. C. Sung, A. Tsutsumi, S. Ohba, K. Ueda, W. A. Morrison, Plast. Reconstr. Surg. 2003, 112, 1636.

[27] E. M. Brey, S. Uriel, H. P. Greisler, L. V. Mclntire, Tissue Eng. 2005, $11,567$.
[28] M. E. Francis-Sedlak, M. L. Moya, J. J. Huang, S. A. Lucas, N. Chandrasekharan, J. C. Larson, M. H. Cheng, E. M. Brey, Microvasc. Res. 2010, 80, 3.

[29] H. F. Dvorak, M. Detmar, K. P. Claffey, J. A. Nagy, L. van de Water, D. R. Senger, Int. Arch. Allergy Immunol. 1995, 107, 233.

[30] C. R. Ozawa, A. Banfi, N. L. Glazer, G. Thurston, M. L. Springer, P. E. Kraft, D. M. McDonald, H. M. Blau, J. Clin. Investig. 2004, 113, 516.

[31] T. P. Richardson, M. C. Peters, A. B. Ennett, D. J. Mooney, Nat. Biotech. 2001, 19, 1029.

[32] M. Ehrbar, A. Metters, P. Zammaretti, J. A. Hubbell, A. H. Zisch, J. Controlled Release 2005, 101, 93.

[33] M. J. Cross, L. Claesson-Welsh, Trends Pharmacol. Sci. 2001, 22, 201.

[34] E. A. Phelps, A. J. García, Curr. Opin. Biotechnol. 2010, 21, 704

[35] N. K. Ferrara, S. Robert, Nature 2005, 438, 7.

[36] J. Rouwkema, N. C. Rivron, C. A. van Blitterswijk, Trends Biotechnol. 2008, 26, 434.

[37] J. J. Moon, J. E. Saik, R. A. Poché, J. E. Leslie-Barbick, S.-H. Lee, A. A. Smith, M. E. Dickinson, J. L. West, Biomaterials 2010, 31, 3840.

[38] K. Y. Lee, S. H. Yuk, Prog. Polym. Sci. 2007, 32, 669.

[39] A. Perets, Y. Baruch, F. Weisbuch, G. Shoshany, G. Neufeld, S. Cohen, J. Biomed. Mater. Res., Part A 2003, 65A, 489.

[40] S. Young, M. Wong, Y. Tabata, A. G. Mikos, J. Controlled Release 2005, 109, 256.

[41] L. L. Y. Chiu, R. D. Weisel, R.-K. Li, M. Radisic, J. Tissue Eng. Regenerative Med. 2011, 5, 69.

[42] A. Zieris, S. Prokoph, K. R. Levental, P. B. Welzel, M. Grimmer, U. Freudenberg, C. Werner, Biomaterials 2010, 31, 7985.

[43] D. B. Pike, S. Cai, K. R. Pomraning, M. A. Firpo, R. J. Fisher, X. Z. Shu, G. D. Prestwich, R. A. Peattie, Biomaterials 2006, 27, 5242

[44] J. Taipale, J. Keski-Oja, FASEB J. 1997, 11, 51.

[45] K. Ono, H. Hattori, S. Takeshita, A. Kurita, M. Ishihara, Glycobiology 1999, 9, 705.

[46] B. Brandner, R. Kurkela, P. Vihko, A. J. Kungl, Biochem. Biophys. Res. Commun. 2006, 340, 836.

[47] C. Ruhrberg, H. Gerhardt, M. Golding, R. Watson, S. Ioannidou, H. Fujisawa, C. Betsholtz, D. T. Shima, Genes Dev. 2002, 16, 2684.

[48] J. Lee, J. J. Yoo, A. Atala, S. J. Lee, Biomaterials 2012, 33, 6709.

[49] A. Lode, A. Reinstorf, A. Bernhardt, C. Wolf-Brandstetter, U. König, M. Gelinsky, J. Biomed. Mater. Res., Part A 2008, 86A, 749.

[50] S. Singh, B. M. Wu, J. C. Y. Dunn, Biomaterials 2011, 32, 2059.

[51] C. J. Robinson, B. Mulloy, J. T. Gallagher, S. E. Stringer, J. Biol. Chem. 2006, 281, 1731.

[52] W. Zhao, S. A. McCallum, Z. Xiao, F. Zhang, R. J. Linhardt, Biosci. Rep. 2012, 32, 10

[53] J. B. Gurdon, P.-Y. Bourillot, Nature 2001, 413, 6.

[54] C. R. Ozawa, A. Banfi, N. L. Glazer, G. Thurston, M. L. Springer, P. E. Kraft, D. M. McDonald, H. M. Blau, J. Clin. Investig. 2004, 113, 516.

[55] R. R. Chen, E. A. Silva, W. W. Yuen, A. A. Brock, C. Fischbach, A. S. Lin, R. E. Guldberg, D. J. Mooney, FASEB J. 2007, 21, 3896.

[56] L. M. Weber, C. G. Lopez, K. S. Anseth, J. Biomed. Mater. Res., Part A 2009, 90, 720.

[57] S. V. Bhujbal, B. de Haan, S. P. Niclou, P. de Vos, Sci. Rep. 2014, 4, 6856.

[58] G. A. Paredes-Juarez, N. M. Sahasrabudhe, R. S. Tjoelker, B. J. de Haan, M. A. Engelse, E. J. de Koning, M. M. Faas, P. de Vos, Sci. Rep. 2015, 5, 14623.

[59] C. J. Kirkpatrick, S. Fuchs, R. E. Unger, Adv. Drug Deliv. Rev. 2011 63, 291.

[60] A. H. Ropper, K. C. Gorson, C. L. Gooch, D. H. Weinberg, A. Pieczek, J. H. Ware, J. Kershen, A. Rogers, D. Simovic, P. Schratzberger, R. Kirchmair, D. Losordo, Ann. Neurol. 2009, 65, 386.

[61] C. Rinsch, P. Quinodoz, B. Pittet, N. Alizadeh, D. Baetens, D. Montandon, P. Aebischer, M. S. Pepper, Gene Ther. 2001, 8, 523. 
[62] V. Chan, P. Zorlutuna, J. H. Jeong, H. Kong, R. Bashir, Lab Chip 2010, 10, 2062.

[63] A. T. Alsop, J. C. Pence, D. W. Weisgerber, B. A. C. Harley, R. C. Bailey, Acta Biomater. 2014, 10, 4715.

[64] H. Sekine, T. Shimizu, K. Sakaguchi, I. Dobashi, M. Wada, M. Yamato, E. Kobayashi, M. Umezu, T. Okano, Nat. Commun. 2013, 4, 1399.

[65] E. A. Silva, D. J. Mooney, Biomaterials 2010, 31, 1235.

[66] J. E. Leslie-Barbick, J. J. Moon, J. L. West, J. Biomater. Sci. Polym. Edn. 2009, 20, 1763.

[67] R. J. DeVolder, A. T. Zill, J. H. Jeong, H. Kong, Biomaterials 2012, 33, 7718.

[68] M. N. Nakatsu, R. C. A. Sainson, J. N. Aoto, K. L. Taylor, M. Aitkenhead, S. Pérez-del-Pulgar, P. M. Carpenter, C. C. W. Hughes, Microvasc. Res. 2003, 66, 102.

\section{www.MaterialsViews.com}

[69] L. L. Chiu, R. D. Weisel, R. K. Li, M. Radisic, J. Tissue Eng. Regenerative Med. 2011, 5, 69.

[70] M. R. Williamson, R. Black, C. Kielty, Biomaterials 2006, 27, 3608.

[71] P. Fiorina, A. M. Shapiro, C. Ricordi, A. Secchi, Am. J. Transplant. 2008, 8, 1990.

[72] S. Veriter, J. Mergen, R. M. Goebbels, N. Aouassar, C. Gregoire, B. Jordan, P. Leveque, B. Gallez, P. Gianello, D. Dufrane, Tissue Eng. Part A 2010, 16, 1503.

[73] A. Gutowska, Y. H. Bae, J. Feijen, S. W. Kim, J. Controlled Release 1992, 22, 95.

[74] R. J. DeVolder, A. T. Zill, J. H. Jeong, H. Kong, Biomaterials 2012, 33, 7718.

[75] D. W. Fraga, O. Sabek, D. K. Hathaway, A. O. Gaber, Transplantation 1998, 65, 1060. 